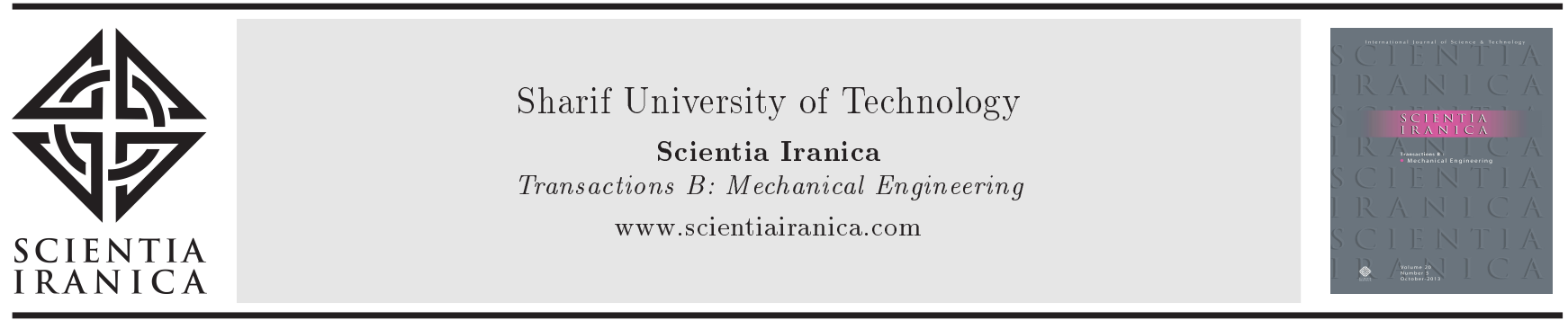

\title{
Analysis of tool wear in ultrasonically assisted turning of $\beta$-Ti-15V-3Al-3Cr-3Sn alloy
}

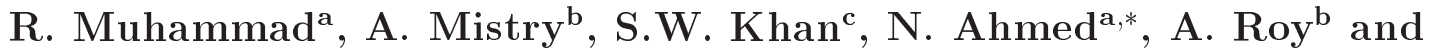 \\ V.V. Silberschmidt ${ }^{b}$ \\ a. Department of Mechanical Engineering, CECOS University of IT and Emerging Sciences, Peshawar, KPK, Pakistan. \\ b. Wolfson School of Mechanical and Manufacturing Engineering, Loughborough University, Leicestershire, LE11 3 TU, UK. \\ c. Department of Civil Engineering, UET Peshawar, KPK, Pakistan.
}

Received 14 January 2015; received in revised form 27 June 2015; accepted 18 October 2015

\section{KEYWORDS}

Titanium alloys;

Tool wear;

Ultrasonically assisted

turning;

Cutting inserts;

Conventional turning.

\begin{abstract}
An extremely high tool wear rate in the machining of titanium alloys ( $\mathrm{Ti}$ alloys) is one of the major reasons limiting the use of conventional machining processes for the components made of these alloys. The machinability of a $\beta-\mathrm{Ti}-15 \mathrm{~V}-3 \mathrm{Al}-3 \mathrm{Cr}-3 \mathrm{Sn}$ ( Ti15333) alloy can be significantly improved using an advanced machining technique known as Ultrasonically Assisted Turning (UAT). The key mechanism of tool wear associated with UAT of Ti-15333 alloy is still unknown. The present study begins to address this issue by examining wear behaviour of two different types of cutting inserts using UAT and Conventional Turning (CT) of Ti-15333 alloy. Tool wear was measured using 3D optical microscope and the composition of the Built-Up Edge (BUE) on the worn tools was analysed with scanning electron microscopy. A robust experimental methodology was developed, which provided repeatable and statistically reliable tool wear results. The KC5510 cutting inserts demonstrated better tool-life in UAT when compared to CP-500 inserts.
\end{abstract}

(C) 2016 Sharif University of Technology. All rights reserved.

\section{Introduction}

In recent decades, machining of the alloys has been a subject of interest in the power-generation, chemical, aerospace, and biomedical industries. The poor machinability of Ti alloys using conventional machining processes is the main disadvantage due to titanium alloys high strength and lower thermal conductivity. A continuous and intensive contact between tool and a workpiece material can generate high cutting forces and temperature in the process zone during titanium alloys machining. This combined effect results in tool surface degradation, poor surface finish of the workpiece, and

*. Corresponding author. Tel.: 0092915860291 E-mail addresses: R.Muhammad@cecos.edu.pk (R. Muhammad); armistry@gmail.com,(A. Mistry); sajjadwali.khan@gmail.com (S.W.Khan); naser@cecos.edu.apk (N.Ahmed);A.Roy3@lboro.ac.uk (A Roy); V.Silberschmidt@lboro.ac.uk (V.V. Silberschmidt) ultimately, tool failure. In softer materials, the effect of tool wear is less intensive because the contact pressure between the tool and workpiece does not exceed a few megapascals and temperature of the process zone is lower than that of hard-to-cut alloys; in hard-tocut alloys, the temperature usually exceeds $800^{\circ} \mathrm{C}$ and contact pressure can go as high as $10^{3}-2 \times$ $10^{3} \mathrm{MPa}$ [1]. In spite of the technological advancements in investigating tool wear in machining processes, it is still hard to fully understand the mechanism of tool wear in machining processes of metals due to the nonlinear behaviour of the tool and strength of workpiece materials at elevated temperature, high strain/strain rate and the complex nature of tool-workpiece, and tool-chip contacts. A series of assumptions was used by various researchers to explain the physical nature of tool wear at different conditions, including diffusion, abrasion, adhesion, fracture, and crumbling [1,2]. In most cases, the immediate effect of tool wear can be 
found on the rake and flank faces of the cutting tool [35].

The advanced alloys that have more recently been introduced because of demand for high strength and resistance to corrosion present challenges with regard to their machinability with conventional machining processes. High levels of contact pressure and temperature of the process zone result in poor tool-life and surface finish [6]. The recommended cutting speeds and feed rates for finishing processes are in the range of $0.2-0.63 \mathrm{~m} / \mathrm{s}$ and $0.15-0.2 \mathrm{~mm} / \mathrm{rev}$, respectively, for titanium alloys [7-9]. In order to overcome these problems, new cutting-tool materials were introduced to increase tool-life and quality of products [10], conventional and environmentally friendly coolants were used to remove an excess amount of heat generated at the tool workpiece interface [11], and new machining techniques were introduced to improve surface quality and tool-life in machining of hard-to-cut alloys [12-19].

A new machining technique was introduced to improve the machining of hard-to-cut materials called Ultrasonically Assisted Turning (UAT) $[12,13,17,20-$ 27]. UAT transforms a continuous cutting process into a transient one by superimposition of low-amplitude ultrasonic vibration on the movement of a cutting tool, resulting in an intermittent contact between it and a machined workpiece. This new technique has shown significant improvement in surface roughness and reduction in cutting forces in the machining of titaniumand nickel-based alloys. The same idea has also been extended to drilling process, e.g. for carbon-fiberreinforced composite [28]. Most recently, Muhammad et al. $[14,29]$ have introduced a new variant of UAT, called Hot Ultrasonically Assisted Turning (HUAT), which has shown a further reduction in cutting forces and improvement in surface roughness. However, no attempt has been made to investigate the tool-life for this new machining technique.

Hence, the current work presents results of an experimental study of tool wear analysis conducted using two types of cutting inserts (CP500 and KC5510) in conventional turning ( $\mathrm{CT}$ and UAT). Both cutting inserts have PVD-coated with a ceramic layer of ( $T i-$ Al) $N$ over a primer layer of $T i N$, offering the highest resistance to wear [30], where the latter contains cobalt particles in the substrate materials which further enhance its toughness behaviour in intermittent cutting. Usually, the recommended tool for heat resistant alloys in CT processes is CP200. However, tough micrograins in CP500 inserts make them a better choice than hard micro-grains in CP200 inserts in UAT.

\section{Experimental procedures}

\subsection{Workpiece material}

The workpiece used in this study was Ti-15333 alloy, which falls in the class of difficult-to-machine titanium alloys. A $50 \mathrm{~mm}$-bar having a length of $300 \mathrm{~mm}$, solution-treated and aged by annealing at $790^{\circ} \mathrm{C}$ for 30 minutes was selected for this study. The mechanical and thermal properties of the studied alloys are shown in Table 1.

\subsection{Cutting tools}

Two types of inserts were used for machining of Ti15333 alloy and their specification is given in Table 2.

Insert CP-500 is suitable for intermittent cutting as it has a tough micro-grain structure, and the coating technique provides a multiphase coating consisting of a ceramic layer of titanium-aluminium nitride on a layer of titanium nitride. The use of aluminium as a coating material results in an oxide-layer formation, increasing the insert's ability to withstand high cutting temperatures, which are encountered when machining workpieces with low thermal conductivity, e.g. Ti-based alloys. The tool geometry is shown in Figure 1.

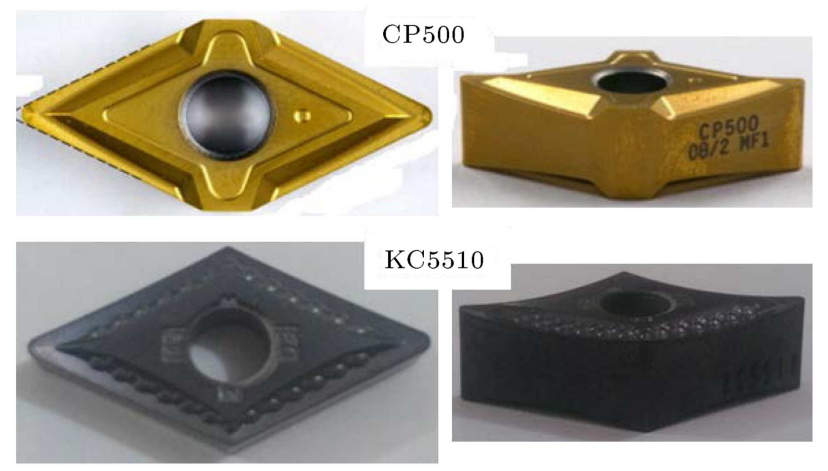

Figure 1. Geometry of inserts.

Table 1. Properties of Ti-15333.

\begin{tabular}{ll}
\hline Workpiece material & Ti-15333 \\
Workpiece diameter, $\boldsymbol{D}(\mathbf{m m})$ & 50 \\
Producer & GfE Metalle and Materialien GmbH \\
Heat treatment & Solution-treated and aged \\
Young's modulus, $\boldsymbol{E}(\mathbf{G P a})$, at room temperature & 87 \\
Density, $\boldsymbol{\rho}\left(\mathbf{k g} / \mathbf{m}^{\mathbf{3}}\right)$ & 4900 \\
Thermal conductivity, $\boldsymbol{k}(\mathbf{W} / \mathbf{k m})$ & 8.08 \\
Ultimate tensile strength, $\boldsymbol{\sigma}_{\boldsymbol{u} \mathbf{1}}(\mathbf{M P a})$ & 1200 \\
\hline
\end{tabular}


Table 2. Specification of cutting inserts.

\begin{tabular}{lll}
\hline \multicolumn{1}{c}{ Specification } & \multicolumn{1}{c}{ Insert 1 } & \multicolumn{1}{c}{ Insert 2 } \\
\hline Manufacturer & SECO & KENNAMETAL \\
Tool part number & DNMG 150608 MF1 CP-500 & DNMG 150608 KC-5510 \\
Insert material & Micro-grained tungsten carbide & Fine-grained tungsten carbide \\
& & $6 \%$ cobalt substrate \\
Coating material & Conventional PVD (Ti, Al)N-TiN & Advanced PVD TiAlN \\
Tool-nose radius, $r_{c}(\mathbf{m m})$ & 0.8 & 0.8 \\
Nose angle $\left({ }^{\circ}\right)$ & 55 & 55 \\
Cutting-edge radius $(\mu \mathbf{m})$ & 25 & 25 \\
Rake angle & $14^{\circ} 6^{\prime}$ & $14^{\circ} 6^{\prime}$ \\
Chamfer angle $\left({ }^{\circ}\right)$ & 0 & 0 \\
\hline
\end{tabular}

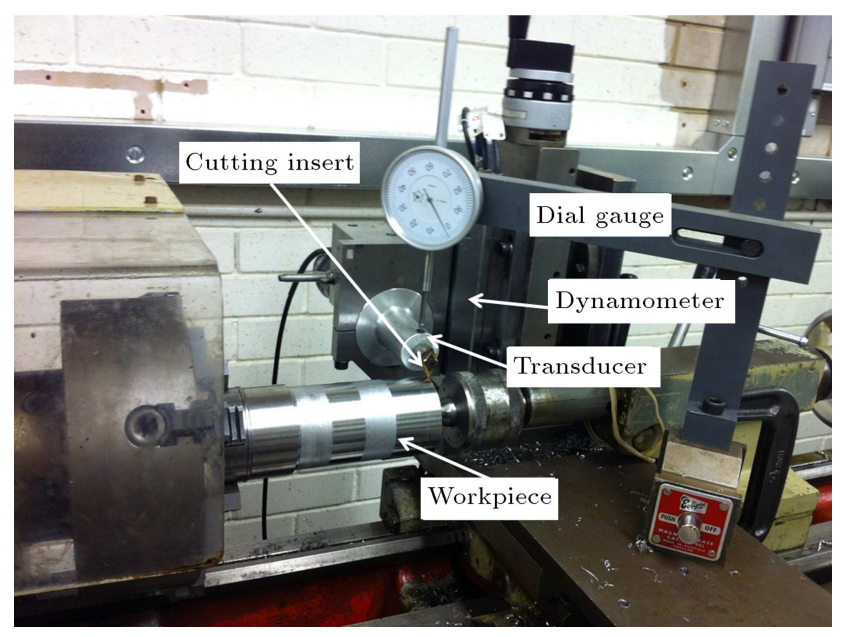

Figure 2. Experimental setup for CT and UAT.

Insert KC5510 is an advanced PVD TiAlN-coated fine-grained tungsten carbide grade. It is specifically engineered for machining of high-temperature Tialloys. The fine-grained tungsten carbide $6 \%$-cobalt substrate has excellent toughness and deformation resistance while the advanced PVD coating allows double speeds for metal cutting when compared to those for conventional PVD-coated cutting tools.

\subsection{Cutting conditions}

Both CT and UAT experiments were performed on a Harrison 300 universal lathe machine using a setup shown in Figure 2. The workpiece was clamped in a four-jaw spindle chuck and a dial-gauge was used to achieve accurate depth of cut in all the experiments. Constant feed rate, $f=100 \mu \mathrm{m} / \mathrm{rev}$, and depth of cut, $a_{p}=300 \mu \mathrm{m}$, were used in experimentation. Vibration with a frequency of $20 \mathrm{kHz}$ and amplitude of $10 \mu \mathrm{m}$ was applied to the cutting inserts in the cutting direction in the UAT regime. The same setup with ultrasonic switched off was used for conventional machining. Two cutting speeds, $10 \mathrm{~m} / \mathrm{min}$ and $30 \mathrm{~m} / \mathrm{min}$, were used in the dry-turning experiments. The test matrix used for tool wear analysis is presented in Table 3 .

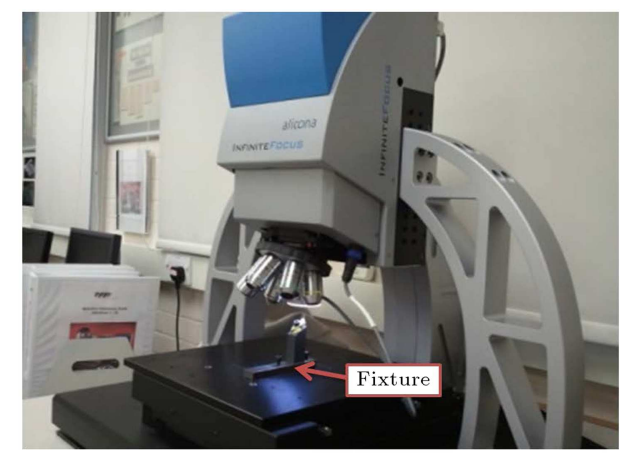

(a)

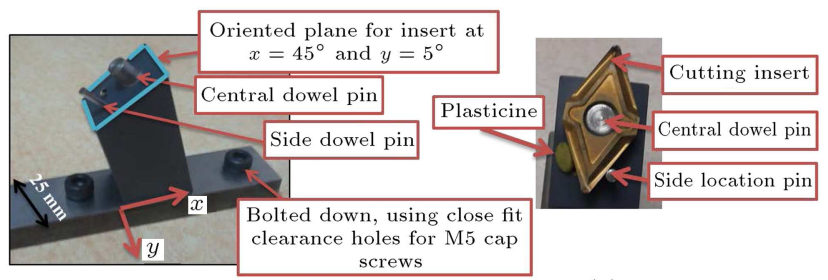

(b)

(c)

Figure 3. (a) Alicona infinite-focus system used for tool wear analysis. (b) Special insert fixture. (c) Cutting insert placed on oriented plane of fixture.

\subsection{Tool-wear measurement}

In this study, a 3D optical measurement system; infinite-focus by Alicona, was used for tool wear analysis (Figure 3(a)). A special tool fixture was designed to ensure accurate positioning of the cutting insert at various stages of its life in experimentation (Figure 3(b)). The orientation of the plane of the fixture (Figure 3(c)) was achieved through a series of trials, carried out on the Alicona infinite-focus system to get a good-quality scan of the inserts. A $5 \mathrm{X}$ objective of the system was used because of its large field of view compared to a 10X objective, and it was found that it was fully capable to cope with the wear-prone region even when the wear progress occurred along the flank face of the cutting edge. A stepwise procedure was used to carry out tool wear analysis in both CT and UAT. Initially, the analysed cutting inserts were given an ultrasonic bath to remove unwanted solid, semi-solid, 
Table 3. Test matrix for tool wear analysis.

\begin{tabular}{|c|c|c|c|c|c|c|c|}
\hline \multirow[b]{2}{*}{$\begin{array}{l}\text { Cutting insert } \\
\text { no. (insert } \\
\text { part name) }\end{array}$} & \multirow[b]{2}{*}{ Edge no. } & \multirow[b]{2}{*}{ Process } & \multirow[b]{2}{*}{$\begin{array}{c}\text { Machining time } \\
t_{m}(\mathrm{~s})\end{array}$} & \multicolumn{4}{|c|}{ Cutting conditions } \\
\hline & & & & $\begin{array}{c}\text { Cutting } \\
\text { speed } \\
(\mathrm{m} / \mathrm{min}) \\
\end{array}$ & $\begin{array}{c}\text { Depth } \\
\text { of cut } \\
(\mu \mathrm{m})\end{array}$ & $\begin{array}{c}\text { Feed } \\
(\mu \mathrm{m} / \mathrm{rev})\end{array}$ & Coolant \\
\hline \multirow{4}{*}{$\begin{array}{c}1(\text { SECO } \\
\text { grade CP500) }\end{array}$} & 1 & $\mathrm{CT}$ & $100 ; 300 ; 500 ; 700$ & 10 & \multirow{8}{*}{300} & \multirow{8}{*}{100} & \multirow{8}{*}{$\begin{array}{c}\text { None } \\
\text { (dry } \\
\text { process) }\end{array}$} \\
\hline & 2 & $\mathrm{CT}$ & $100 ; 300 ; 500 ; 700$ & 30 & & & \\
\hline & 3 & UAT & $100 ; 300 ; 500 ; 700$ & 10 & & & \\
\hline & 4 & UAT & $100 ; 300 ; 500 ; 700$ & 30 & & & \\
\hline \multirow{4}{*}{$\begin{array}{c}2(\mathrm{KENLOC} \\
\text { grade KC5510) }\end{array}$} & 1 & $\mathrm{CT}$ & $100 ; 300 ; 500 ; 700$ & 10 & & & \\
\hline & 2 & $\mathrm{CT}$ & $100 ; 300 ; 500 ; 700$ & 30 & & & \\
\hline & 3 & UAT & $100 ; 300 ; 500 ; 700$ & 10 & & & \\
\hline & 4 & UAT & $100 ; 300 ; 500 ; 700$ & 30 & & & \\
\hline
\end{tabular}

or liquid contaminants, which could include metallic and non-metallic debris, chips, dirt particles, or other elements from the surface of the insert. A cleaning procedure with pressurized air was used to ensure removal of any dirt particles to get more accurate scan of the cutting insert.

The Alicona machine software has an in-built feature known as difference measurement, which is dedicated to volume measurement. This feature was used to calculate the amount of volume reduction for the cutting inserts after machining by comparing a scan of the virgin sample (a reference scan) with that for the used insert. All experiments for CT and UAT were carried out on the in-house state-ofthe-art experimental setup available at Loughborough University, UK. Additional details about the experimental setup can be found elsewhere [12,21]. The experiments were repeated three times for each cutting condition. The spread in data was huge as one of tested KC5510 inserts at both cutting speeds does not fail due to BUE formation. However, the rest of the data was reasonably in good shape and the results were repeatable in both $\mathrm{CT}$ and UAT.

\section{Tool wear results}

Evolution of the average tool wear rate for both cutting inserts (grades CP500 and KC5510) in CT, when machining Ti-15333, is shown in Figure 4. The machining distance (in $\mathrm{m}$ ) on the axis of abscissas is the distance travelled by the cutting insert, which was calculated from the cutting speed and the cutting period that the insert worked for; whereas, the average tool wear rate on the ordinate was then calculated from the experimental data obtained with the Alicona system, using the following equation:

$$
\text { Average tool wear rate }=\frac{\Delta V}{t_{m}} \text {. }
$$

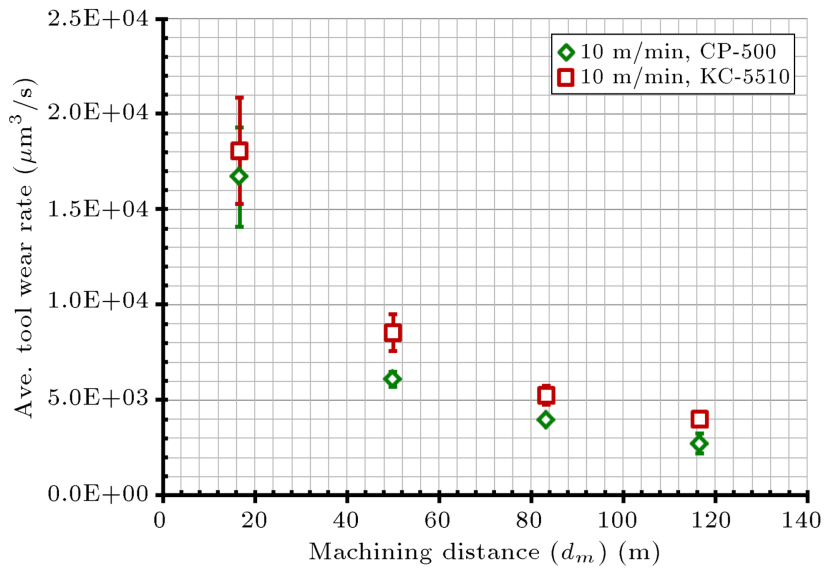

Figure 4. Comparison of tool wear for both inserts at cutting speed of $10 \mathrm{~m} / \mathrm{min}$ in CT.

$\Delta V$ is the average volume reduction in the cutting insert and $t_{m}$ is the total machining time. A lower average tool wear rate in CP-500 cutting insert was observed when compared to that for insert KC5510, resulting in a better tool-life in turning of $\mathrm{Ti}-15333$. Moreover, it can be noticed that for both inserts, the average tool wear rate in the initial distance-travelled interval $16 \mathrm{~m}$ to $50 \mathrm{~m}$ and in the two subsequent intervals (i.e., $50 \mathrm{~m}$ to $83 \mathrm{~m}$ and $83 \mathrm{~m}$ to $116 \mathrm{~m}$ ) attenuated so that it had the lowest magnitude in the last interval. This is an expected phenomenon, since the wear rate under constant load and velocity condition is high during an initial unsteady state and lower in the later, steady-state regime. Similarly, adhesion of material at the tool edge in CT of Ti-15333 also reduced the tool wear rate for both inserts, particularly in CP500. The ultrafine micro-grain structure of KC5510 insert, compared to the micro-grain size of CP500 inserts [31,32], give better tool strength of KC5510 inser; however, more BUE formation tendency in CP500 inserts improve its tool-life in CT whereas the coarse grain size of the workpiece material is the same 


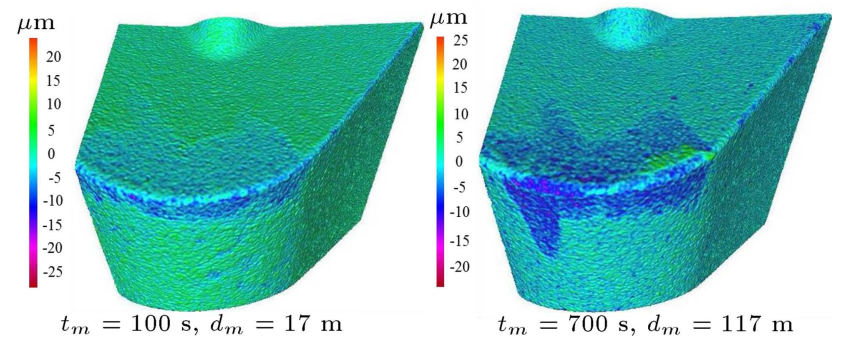

Figure 5. Progression of tool wear in KC5510 at cutting speed of $10 \mathrm{~m} / \mathrm{min}$ in CT.

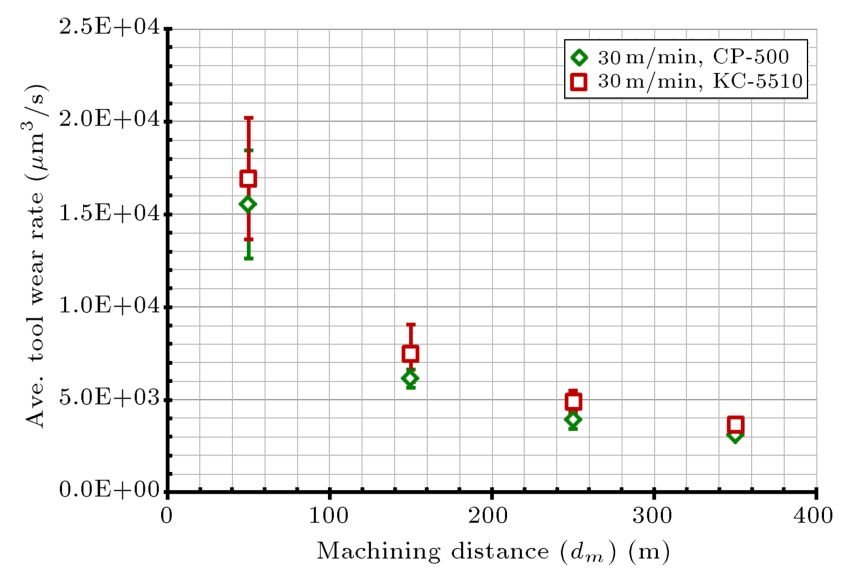

Figure 6. Comparison of tool wear for both inserts in CT at cutting speed of $30 \mathrm{~m} / \mathrm{min}$.

for both inserts [21]. In addition to that, no phase transformation in a machined surface was observed. The difference in the wear rate at the stable state was not significant since only minor removal of coating material with no chipping or crater wear was found on the tools (see Figure 5). However, the tool wear can be significantly higher when the coating is removed [4].

The development of average tool wear rate at a higher cutting speed, $30 \mathrm{~m} / \mathrm{min}$, is shown in Figure 6 for both inserts: CP500 and KC5510. The observations depicted for $30 \mathrm{~m} / \mathrm{min}$ are rather similar to those discussed for a lower speed above. These include the facts that CP500 insert had a lower wear rate and the difference in the wear rate between both inserts was not significant, since only the coating was affected and there was no physical damage to the insert. However, observations during machining tests demonstrated formation of unstable Built-Up Edge (BUE) for both lower and higher cutting speeds, which was due to adhesion of the workpiece material to the rake face of the insert (adhesive wear mechanism). This shows the chemical affinity between materials of the inserts and the workpiece. The BUE for CP500 insert after machining for $500 \mathrm{~s}$ at $30 \mathrm{~m} / \mathrm{min}$ is shown in Figure 7. The height of the added material was $72 \mu \mathrm{m}$ and was calculated using smartscope FLASH 200 system [33].

Transition to vibro-impact machining in the UAT

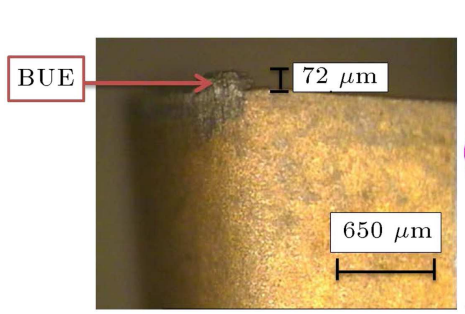

(a)

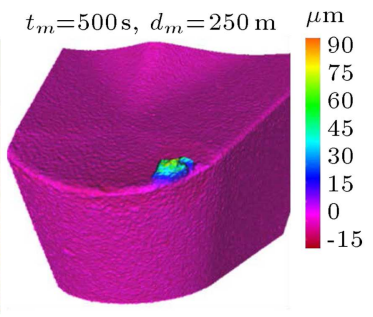

(b)
Figure 7. (a) BUE of CP500 insert at $t_{m}=500 \mathrm{~s}$ and $V=30 \mathrm{~m} / \mathrm{min}$ : image obtained with Smartscope FLASH 200 system. (b) Data obtained with Alicona infinite-focus system.

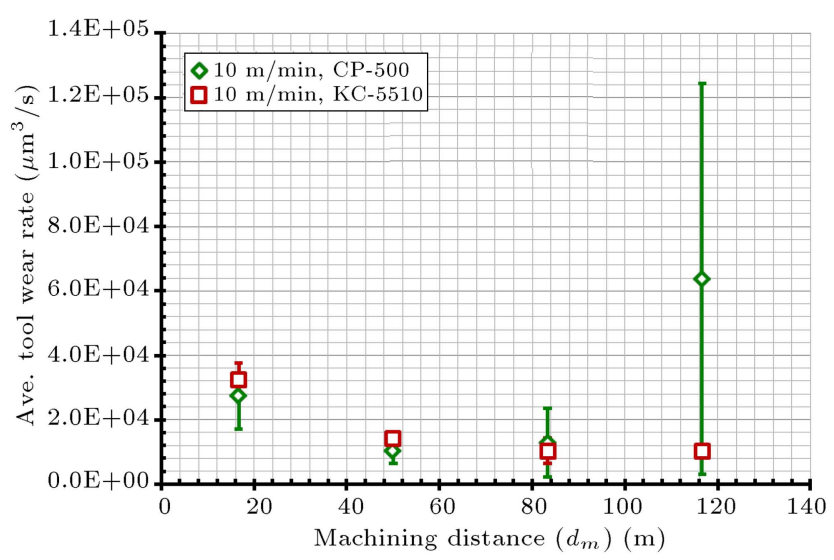

Figure 8. Comparison of tool wear in both inserts in UAT at cutting speed of $10 \mathrm{~m} / \mathrm{min}$.

regime, as expected, affected the character of the tool wear evolution. The development of the average tool wear rate with machined length, when machining Ti15333 using this regime at the lower cutting speed of $10 \mathrm{~m} / \mathrm{min}$, is shown in Figure 8 for both insert types. Generally, the levels of average tool wear rate for insert CP500 were lower than those for KC5510 for the initial distance travelled by the insert up to approximately $50 \mathrm{~m}$; this difference was small. However, when CP500 insert was worked for higher distances, beyond $60 \mathrm{~m}$, its wear rate increased drastically by a factor of more than 6 times between the travelled distances $83 \mathrm{~m}$ and $116 \mathrm{~m}$. This is due to the fact that two of the three CP500 inserts used underwent catastrophic failures as shown in Figure 9. The main reasons for the higher tool wear rate in CP500 inserts are the lack of BUE formation in UAT compared to KC5510 inserts, oxidation of WC tools, and their grain size which is coarser than KC5510 [31,32]. The cobalt content added to KC5510 insert refines its grain size compared to CP500 inserts and gives it more strength and toughness.

For CP500 insert, the catastrophic failure in the form of plastic deformation was linked to the substrate composition of the CP500 insert, which caused significantly lower impact resistance than that of insert 


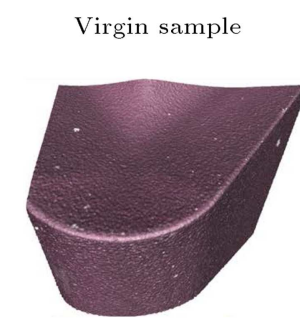

$t_{m}=0 \mathrm{~s}, d_{m}=0 \mathrm{~m}$
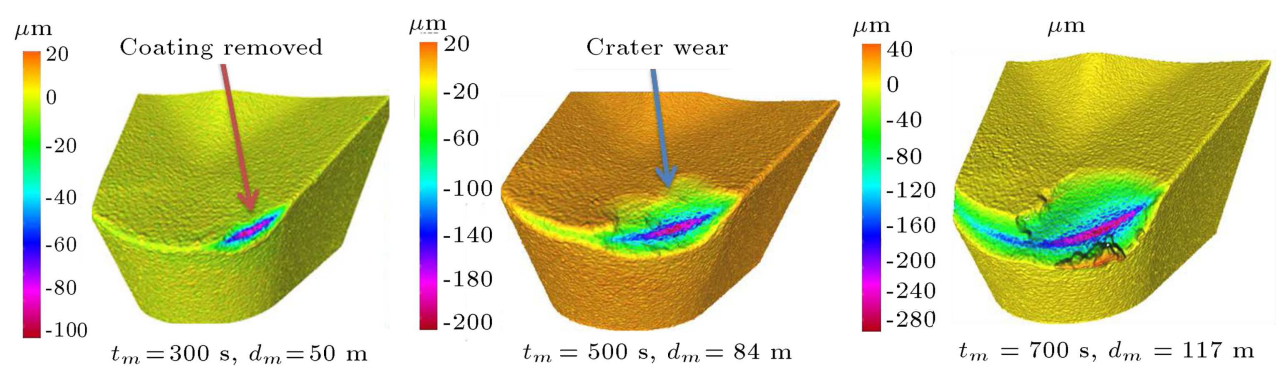

Figure 9. Wear progress to catastrophic failure in CP-500 cutting inserts in UAT at cutting speed of $10 \mathrm{~m} / \mathrm{min}$.

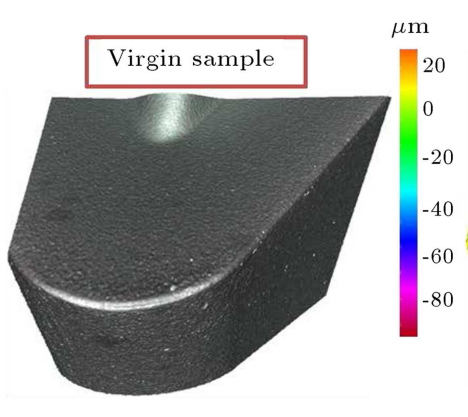

$t_{m}=0 \mathrm{~s}, d_{m}=0 \mathrm{~m}$
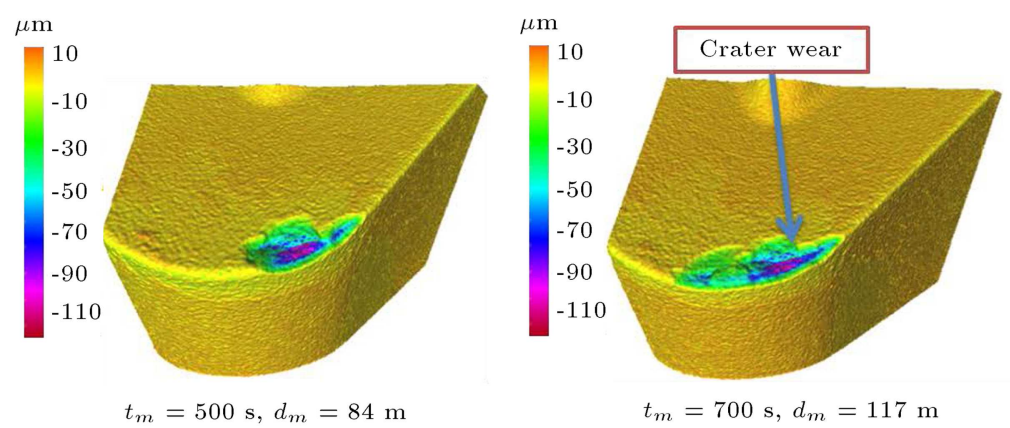

Figure 10. Wear progress of insert KC-5510 in UAT at cutting speed of $10 \mathrm{~m} / \mathrm{min}$.

KC5510 [34]. This phenomenon can be explained by considering wear progress with the worked time. It was observed that the $\mathrm{Ti}(\mathrm{AlN})$-TiN coating was removed at $300 \mathrm{~s}$ of the worked time. The reason for the quick removal is the brittleness of the thin layer of aluminium oxide. Since, the insert was developed for conventional machining operations and was not designed to withstand multiple micro-impacts characteristic to UAT. When it lost its structural integrity, high temperature in the process zone resulted in a swift removal of the coating from the cutting inserts. Once the coating failed, the substrate of the inserts was exposed to high cutting forces and excessive temperature leading to fast tool failure. As a result, a crater and flank wear were observed along the cutting edge as shown in Figure 9.

In contrast, for KC5510 cutting inserts, it was observed that the average wear rate attenuated by nearly $2 \times 10^{4} \mu \mathrm{m}^{3} / \mathrm{sec}$ at distance $50 \mathrm{~m}$ compared to that at $16 \mathrm{~m}$ and, additionally, by nearly $2 \times 10^{2} \mu \mathrm{m}^{3} / \mathrm{sec}$ at a distance of $83 \mathrm{~m}$. This is beneficial, since it results in a longer tool-life. This extremely positive tool wear behaviour of KC5510 insert, as compared to that of CP500, can be explained by its substrate composition [34]. Similarly, the BUE formation in UAT of KC5510 was frequently observed when compared to CP500 which added life to these types of inserts at higher speeds in turning of $\mathrm{Ti}$ alloys. The wear development in the KC5510 cutting insert is shown in Figure 10. Crater wear was mainly responsible for the failure $(90 \mu \mathrm{m}[35])$ of KC5510 cutting inserts in UAT of Ti-15333.

Comparing the wear progress in two studied inserts, a significant difference was observed in UAT. Though the coating was eventually removed from both inserts, the substrate of insert KC5510 demonstrated significantly greater resistance to localized plastic deformation as well as resistance to failure once the physical damage began $[34,36]$.

The discussed tool wear evolution in CP500 exacerbated at a higher cutting speed of $30 \mathrm{~m} / \mathrm{min}$ as shown in Figure 11. It was observed that for KC5510 insert, 


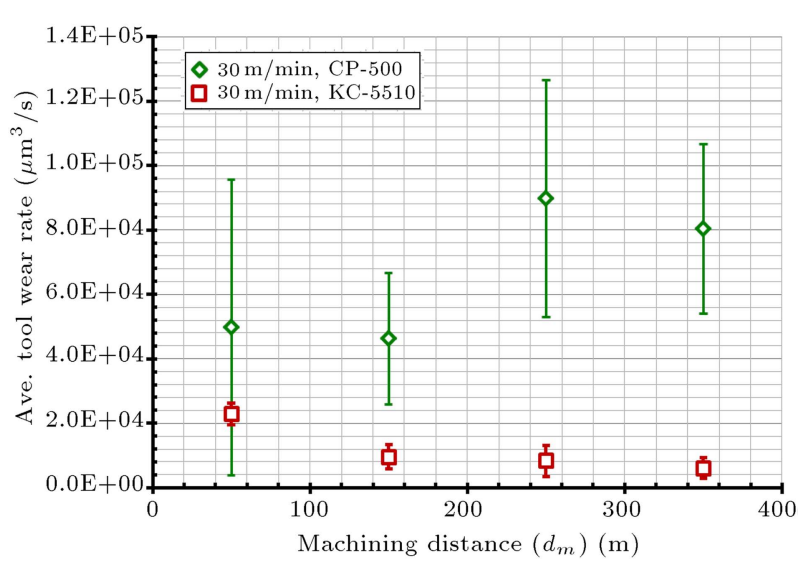

Figure 11. Comparison of tool wear in both inserts in UAT at cutting speed of $30 \mathrm{~m} / \mathrm{min}$.

the average wear rate was significantly lower than that observed for CP500 inserts; it attenuated gradually with increase in the distance travelled by the insert. It is a very positive result implying that KC5510 could enable higher cutting speeds in machining Ti-15333, increasing productivity by achieving higher material removal rate (it was shown [21,37] that UAT resulted in a large force reduction and improvement of surface finish in these tests). In contrast, the tool wear in CP500 inserts was characterised by a rapid increase in the wear rate, more than an order of magnitude higher than that for KC5510 for the same travelled distance of $250 \mathrm{~m}$.

The CP550 inserts at a cutting speed of $30 \mathrm{~m} / \mathrm{min}$ demonstrated increased chipping and flaking, and even- tually catastrophic fracture of the insert occurred. This is depicted in Figure 12 for one of the CP500 inserts, which was worked for $100 \mathrm{~s}, 300 \mathrm{~s}$, and $500 \mathrm{~s}$. The average wear rate for CP500 was higher at $30 \mathrm{~m} / \mathrm{min}$ due to higher cutting temperature and thermal as well as mechanical stresses at high.

Heavy chipping was already observed when the insert was worked for $100 \mathrm{~s}$ (see Figure 13), and the wear manifested itself as rake-face wear initially, due to high temperature and stress at the insert-chip contact on the rake face. Also, it can be seen that the protruding material was observed, most probably the chip/workpiece material welded onto the rake face. To confirm the presence of an external workpiece material on the insert, an analysis has been done on the BUE using Scanning Electronic Microscopy (SEM) (see more below). In the insert worked for $300 \mathrm{~s}$ and $500 \mathrm{~s}$, crater wear and catastrophic fracture are the dominant features in tool failure. Some of the prominent wear mechanisms observed for CP500 insert at high cutting speed were abrasive wear (as chipping occurred), thermal mechanisms (high cutting temperature at high speed), attrition (removal of grains of tool material by the adherent chip), and adhesive wear (at tool-chip interface).

The formation of BUE in UAT of Ti-15333 using KC5510 cutting inserts is an unstable process, which results in a decrease in the average tool wear rate of KC5510 cutting inserts at higher cutting speeds. In most cases, the BUE was welded to the rake face of the cutting inserts as shown in Figure 13.
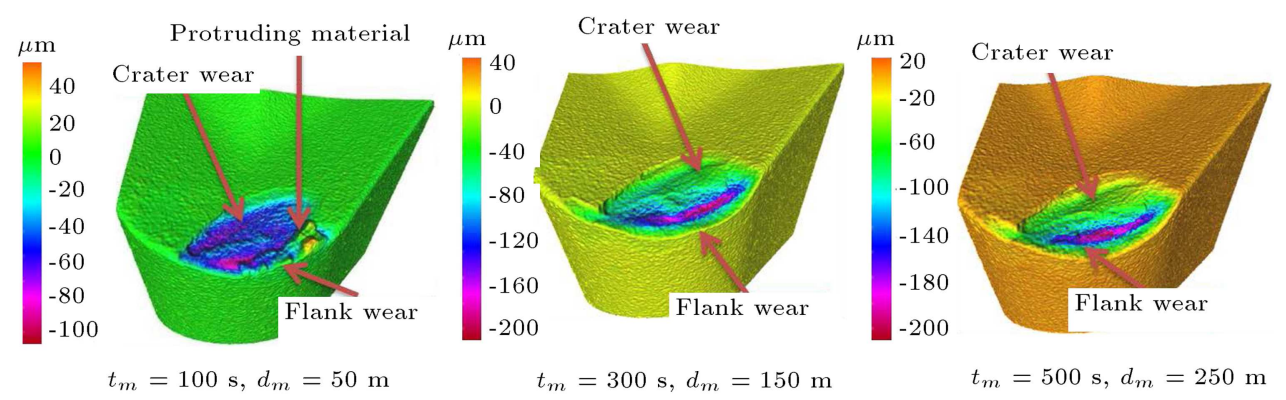

Figure 12. Wear progress of insert CP-500 at cutting speed of $30 \mathrm{~m} / \mathrm{min}$ in UAT.
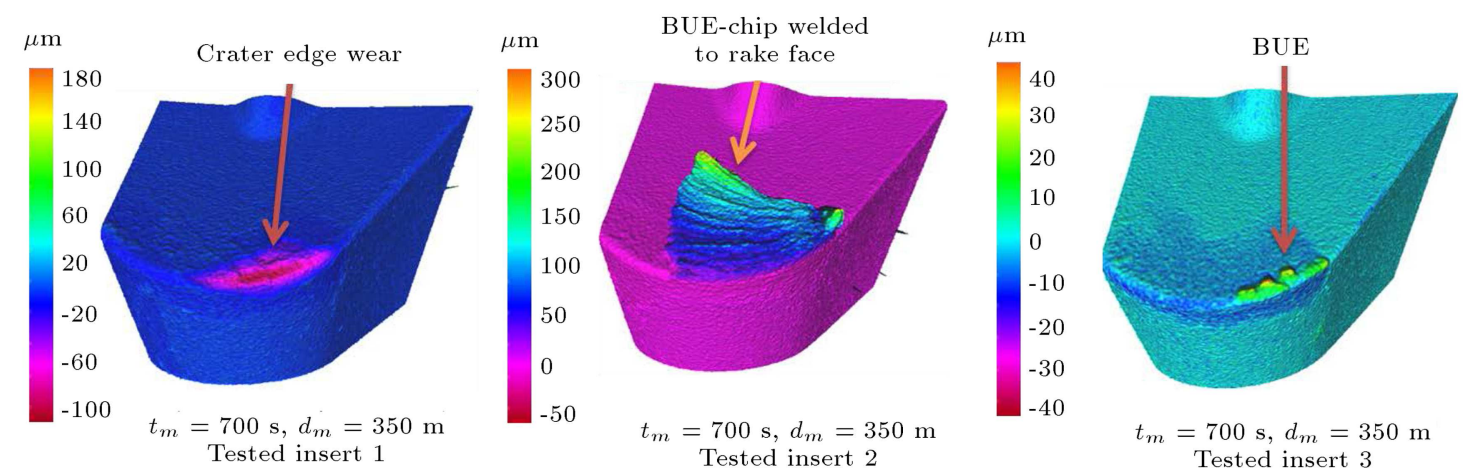

Figure 13. Wear progress of insert KC-5510 at cutting speed of at $30 \mathrm{~m} / \mathrm{min}$ in UAT. 


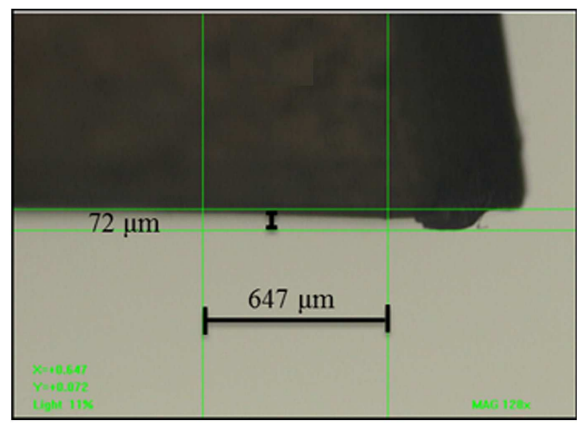

(a)

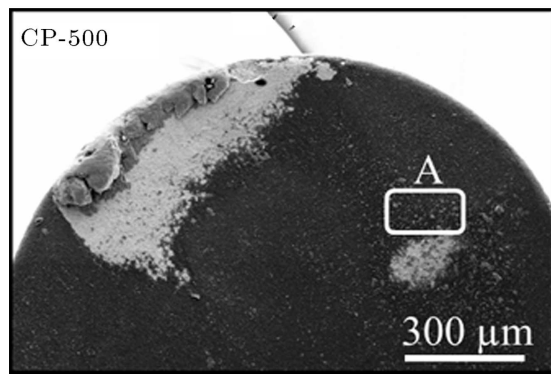

(c)

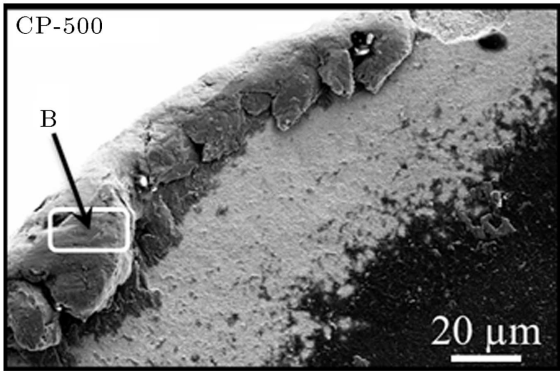

(e)

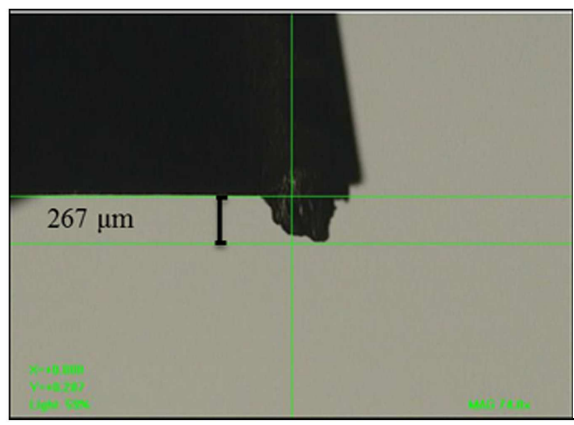

(b)

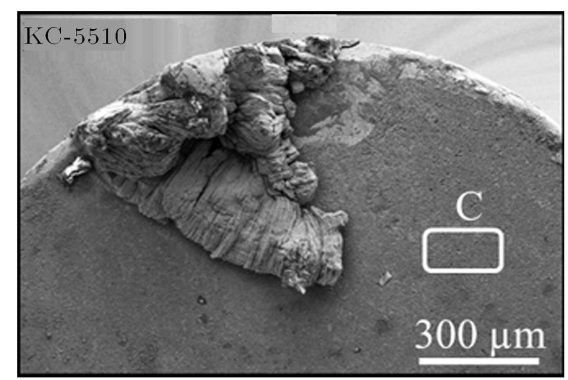

(d)

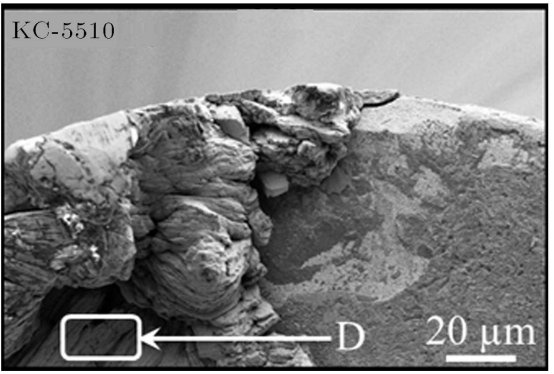

(f)

Figure 14. SEM micrographs depicting BUE formed on inserts CP500 ((a), (c), and (e)) and KC5510 ((b), (d), and (f)).

Table 4. Insert specifications and cutting conditions: analysed for BUE.

\begin{tabular}{lcc}
\hline \multicolumn{1}{c}{ Insert type } & CP500 & KC5510 \\
\hline Machining process & CT & UAT \\
Cutting speed (m/min) & 30 & 10 \\
Worked time (s) & 500 & 500 \\
Feed rate $(\mathrm{mm} / \mathrm{rev})$ & 0.1 & 0.1 \\
\hline
\end{tabular}

\section{SEM analysis of BUE formation}

The formation of BUE was observed in both CT and UAT processes, and was unpredictable since it formed randomly during the experiments at both high $(30 \mathrm{~m} / \mathrm{min})$ and low $(10 \mathrm{~m} / \mathrm{min})$ cutting speeds. Two inserts, one for each machining process, were selected and used for SEM analysis (see Table 4).

The protruding height of BUE and magnified images of their surface profiles for both inserts are shown in Figure 14. Comparing Figure 14(a) and 14(b), it was observed that insert KC5510's BUE protrudes more by about $195 \mu \mathrm{m}$ compared to that for CP500. Moreover, it can be stated that along the rake face, transferred material is present in the form of highly deformed attached chunks for both inserts. This is a typical feature of adhesive wear, which occurs due to bonding or micro welding at surface asperities of contacting bodies, i.e. chip and insert. The high levels of cutting temperature and stresses at the toolchip interface assisted this process. Further analysis was carried out to investigate the composition of the material added to the rake face of the tool in the form of BUE. Therefore, Energy-Dispersive X-ray (EDX) spectroscopy was carried out in the selected regions (marked A, B, C, and D) as shown in Figure 14.

The spectra results show the elemental weights (wt.\%) present in the selected regions. Considering Table 5, elements $\mathrm{Ti}, \mathrm{Al}$, and $\mathrm{N}$ are present in larger elemental weights with minor traces of other elements. This is expected as both inserts have an outer coating of TiAlN for improved hot hardness and wear resistance. Table 6 shows that the BUE on both inserts had 
Table 5. EDX results of inserts CP500 and KC5510 (wt $\%$ ).

\begin{tabular}{ccccc}
\hline Elements & Ti & N & Al & V \\
\hline Region A, CP500 & 61.8 & 19.9 & 17.3 & 0.7 \\
Region C, KC5510 & 46 & 15.7 & 30.1 & 0.8 \\
\hline
\end{tabular}

Table 6. EDX results of BUE for inserts CP500 and KC5510 (wt\%).

\begin{tabular}{cccccccc}
\hline Elements & Ti & V & Sn & Al & Cr & Fe & W \\
\hline $\begin{array}{c}\text { Region B, } \\
\text { CP500 }\end{array}$ & 75.7 & 14.9 & 3.3 & 3 & 2.5 & 0.3 & 0.2 \\
$\begin{array}{c}\text { Region D, } \\
\text { KC5510 }\end{array}$ & 75.4 & 15.8 & 2.6 & 2.3 & 2.1 & 0.4 & 0.2 \\
\hline
\end{tabular}

significantly increased amount of $\mathrm{Ti}$, about $75 \%$ by weight, and elements $\mathrm{Sn}, \mathrm{Cr}$, and $\mathrm{V}$ in noticeable fractions. This confirmed that BUE was composed of transferred workpiece material - Ti15333.

\section{Conclusions}

The main conclusions of this work are:

- The prominent wear mechanism for CP500 and KC5510 cutting inserts in UAT at $10 \mathrm{~m} / \mathrm{min}$ and $30 \mathrm{~m} / \mathrm{min}$ was attrition wear where the particles were pulled out from the substrate;

- A catastrophic tool failure was observed in both tools once the tool coating was removed in UAT. However, the level of wear was significantly higher in CP500 cutting insert than in KC5510;

- The experimental results demonstrated that KC5510 cutting insert exhibited lower tool wear levels at $30 \mathrm{~m} / \mathrm{min}$ when compared to $10 \mathrm{~m} / \mathrm{min}$, indicating its potential for improved material removal rate in UAT;

- In UAT, CP500 cutting insert showed poor wear resistance and readily experienced catastrophic failure at both cutting speeds;

- The average tool wear rate was higher for UAT than for CT for both inserts, though KC5510 demonstrated a performance not much worse than in conventional turning. Obviously, both types of cutting inserts were designed for conventional machining processes and their brittle coatings performed poorly in a vibro-impact regime of UAT. This finding supports a need for the design of tools, specially aimed at UAT.

\section{References}

1. Luo, S.Y., Liao, Y.S. and Tsai, Y.Y. "Wear characteristics in turning high hardness alloy steel by ceramic and CBN tools", J. of Mater. Proc. Tech., 88(1-3), pp. 114-121 (1999).

2. Dolinšek, S., Šuštaršič, B. and Kopač, J. "Wear mechanisms of cutting tools in high-speed cutting processes", Wear, 250(1-12), pp. 349-356 (2001).

3. Coelho, R.T., Ng, E.-G. and Elbestawi, M.A. "Tool wear when turning hardened AISI 4340 with coated PCBN tools using finishing cutting conditions", Int. J. of Mach. Tools and Manuf., 47(2), pp. 263-272 (2007).

4. Mkaddem, A., Ben Soussia, A. and El Mansori, M. "Wear resistance of CVD and PVD multilayer coatings when dry cutting fiber reinforced polymers (FRP)", Wear, 302(1-2), pp. 946-954 (2013).

5. Joshi, R.S. and Singh, H. "An investigation on flank wear mechanism of tungsten carbide drills during conventional and modulation assisted drilling", Mach. Sci. and Tech., 18(1), pp. 99-119 (2014).

6. Özel, T. "Computational modelling of 3D turning: Influence of edge micro-geometry on forces, stresses, friction and tool wear in PcBN tooling", J. of Mater. Proc. Tech., 209, pp. 5167-5177 (2009).

7. Donachie, M.J., Titanium-A Technical Guide, 2nd Ed., ASM International, Ohio, USA (2004).

8. Ezugwu, O. and Wang, M. "Titanium alloys and their machinability-a review", J. of Mater. Proc. Tech., 68(3), pp. 262-274 (1997).

9. Maurotto, A., Siemers, C., Muhammad, R., Roy, A. and Silberschmidt, V. "Ti alloy with enhanced machinability in UAT turning", Metall. and Mater. Trans. A, 45(6), pp. 2768-2775 (2014).

10. Zimmermann, M., Lahres, M., Viens, D.V. and Laube, B.L. "Investigations of the wear of cubic boron nitride cutting tools using Auger electron spectroscopy and Xray analysis by EPMA", Wear, 209(1-2), pp. 241-246 (1997).

11. Shokrani, A., Dhokia, V. and Newman, S.T. "Environmentally conscious machining of difficult-to-machine materials with regard to cutting fluids", Int. J. of Mach. Tools and Manuf., 57, pp. 83-101 (2012).

12. Muhammad, R., Hussain, M.S., Maurotto, A., Siemers, C., Roy, A. and Silberschmidt, V. "Analysis of free machining of $\alpha+\beta$ Ti-alloy using conventional and ultrasonically assisted turning", J. of Mater. Proc. Tech., 214(4), pp. 906-915 (2014).

13. Muhammad, R., Roy, A. and Silberschmidt, V.V. "Finite element modelling of conventional and hybrid oblique turning processes of titanium alloy", Proc. CIRP, 8, pp. 509-514 (2013).

14. Muhammad, R., Maurotto, A., Roy, A. and Silberschmidt, V.V. "Hot ultrasonically assisted turning of $\beta$-Ti alloy", Proc. CIRP, 1, pp. 336-341 (2012).

15. Dhananchezian, M. and Pradeep Kumar, M. "Cryogenic turning of the Ti-6Al-4V alloy with modified cutting tool inserts", Cryogenics, 51(1), pp. 34-40 (2011). 
16. Sun, S., Brandt, M. and Dargusch, M.S. "Thermally enhanced machining of hard-to-machine materials - A review", Int. J. of Mach. Tools and Manuf., 50(8), pp. 663-680 (2010).

17. Shamoto, E., Ma, C. and Moriwaki, T. "Elliptical vibration cutting (3rd report) - Application to threedimensional cutting and investigation of practical effects", Seimitsu Kogaku Kaishi/J. of the Japan Soc. for Prec. Engr., 65(4), pp. 586-591 (1999).

18. Chryssolouries, G., Anifantis, N. and Karagiannis, S. "Laser assisted machining: an overview", J. of Manuf. Sci. and Engr., Trans. of the ASME, 119, pp. 766-769 (1997).

19. Shokrani, A., Dhokia, V., Muñoz-Escalona, P. and Newman, S.T. "State-of-the-art cryogenic machining and processing", Int. J. of Comp. Integ. Manuf., pp. 1-33 (2013).

20. Muhammad, R., Demiral, M., Roy, A. and Silberschmidt, V.V. "Modelling the dynamic behaviour of hard-to-cut alloys under conditions of vibro-impact cutting", J. of Phy.: Conf. Ser., 451, pp. 1-11 (2013).

21. Maurotto, A., Muhammad, R., Roy, A. and Silberschmidt, V.V. "Enhanced ultrasonically assisted turning of a $\beta$-titanium alloy", Ultrasonics, 53(7), pp. 1242-1250 (2013).

22. Nategh, M.J., Razavi, H. and Abdullah, A. "Analytical modeling and experimental investigation of ultrasonicvibration assisted oblique turning, part I: Kinematics analysis", Int. J. of Mech. Sci., 63(1), pp. 1-11 (2012).

23. Muhammad, R., Maurotto, A., Roy, A. and Silberschmidt, V.V. "Ultrasonically assisted turning of Ti6Al-2Sn-4Zr-6Mo", J. of Phy.: Conf. Ser., 382, pp. 1-8 (2012).

24. Muhammad, R., Ahmed, N., Roy, A. and Silberschmidt, V.V. "Turning of advanced alloys with vibrating cutting tool", Solid State Phenom., 188, pp. 277-284 (2012).

25. Muhammad, R., Ahmed, N., Roy, A. and Silberschmidt, V.V. "Numerical modelling of vibrationassisted turning of Ti-15333", Proc. CIRP, 1, pp. 347352 (2012).

26. Muhammad, R., Demiral, M., Ahmed, N., Roy, A. and Silberschmidt, V.V. "Computational study of ultrasonically-assisted turning of Ti alloys", Adv. Mater. Res., 223, pp. 30-36 (2011).

27. Sharman, A., Bowen, P., Aspinwall, D. and Dewes, C., Ultrasonic Assisted Turning of Gamma Titanium Aluminide, Rolls-Royce PLC (2001).

28. Phadnis, V.A., Makhdum, F., Roy, A. and Silberschmidt, V.V. "Experimental and numerical investigations in conventional and ultrasonically assisted drilling of CFRP laminate", Proc. CIRP, 1, pp. 455459 (2012).

29. Muhammad, R., Maurotto, A., Roy, A. and Silberschmidt, V.V. "Analysis of forces in vibro-impact and hot vibro-impact turning of advanced alloys", App. Mech. and Mater., 70, pp. 315-320 (2011).
30. Joshi, A. and Hu, H.S. "Oxidation behavior of titanium-aluminium nitrides", Surf. and Coat. Tech., 76-77, pp. 499-507 (1995).

31. "MSC. MSC Industrial supply company-KENNAMETAL", Available at: http://www.mscdirect.com/ product/08455941? fromRR=Y (2013).

32. "Seco-Tool. Seco catalogue", Available at: http://ecat. secotools.com/ (2013).

33. "Optical-gagging-products. Optical gagging products, Multisensor measurement for manufacturing professionals", Available at: http://www.ogpnet.com/ ogpVidFlash200.jsp (2013).

34. Exner, H.E. and Gurland, J.A. "A review of parameters influencing some mechanical properties of tungsten carbide cobalt alloys", Powd. Metall., 13, pp. 13-31 (1970).

35. ISO, "Tool life testing with single-point turning tools", in International Standard No. 3685, 2nd Edn. (1993).

36. Mills, B. and Redford, A.H., Machinability of Engineering Materials, London, New York, Applied Science Publishers (1983).

37. Muhammad, R., Maurotto, A., Demiral, M., Roy, A. and Silberschmidt, V. "Thermally enhanced ultrasonically assisted machining of $\mathrm{Ti}$ alloy", CIRP J. of Manuf. Sci. and Tech., 7(2), pp. 159-167 (2014).

\section{Biographies}

Riaz Muhammad graduated in Mechanical Engineering with distinction from UET Peshawar, Pakistan, in 2006, followed by his Master and PhD degrees in Mechanical Engineering from Ghulam Ishaq Khan Institute of Science and Technology (GIKI) and Loughborough University in 2009 and 2013, respectively. $\mathrm{He}$ is currently working as an Associate Professor in the Department of Mechanical Engineering, CECOS University of IT and Emerging Sciences, Pakistan. His research activities include finite element modelling, hybrid machining process, composite, polymers, and biomedical materials.

Antriksh Mistry received his BS degree in Mechanical Engineering from Loughborough University,UK, in 2013. His research interest includes metrology and machining processes.

Sajjad Wali Khan received his BS degree in Civil Engineering from UET Peshawar in 2007. He received his $\mathrm{PhD}$ degree form Loughborough University, UK, in 2013. He is currently an Assistant Professor in the Department of Civil Engineering, UET Peshawar. His research interests include concrete, wire ropes, and metrology.

Naseer Ahmed received his BS and MS degrees in Mechanical Engineering from UET Peshawar and 
GIKI, respectively. He received his $\mathrm{PhD}$ degree form Loughborough University, UK, in 2007. He is Professor of Manufacturing at CECOS University, Pakistan, head of Mechanics of Advanced Materials and Manufacturing Research Group (AM2RG), and director of research and development. His research activities include manufacturing, biomedical materials, composite materials, and assisted machining processes.

Anish Roy received his B.Tech. (Hons.) in Civil and Environmental Engineering from Indian Institute of Technology, Kharagpur, India, in 1999. He received his MS degree in Civil and Environmental Engineering from Carnegie Mellon University, USA, in 2003. He received his $\mathrm{PhD}$ degree from Carnegie Mellon University, USA, in 2005 in Computational Science and Engineering. His research interest includes ultrasonically assisted turning and drilling, computational mechanics, and mechanics of materials.

Vadim Silberschmidt received his MEng and $\mathrm{PhD}$ at Perm Technical University (USSR). After working at the USSR (Russian) Academy of Science and Technical University Munich, Germany, in 2000, he joined Loughborough University, UK, as Professor of Mechanics of Materials and Head of Mechanics of Advanced Materials Research Group. He is a Charted Engineer, Fellow of the Institution of Mechanical Engineers and Institute of Physics. He is editor-in-chief of "Mechanics of Advanced Materials and Modern Processes" and Associate Editor of other three international journals. His research activities cover mechanics and micromechanics of advanced engineering materials and biomaterials. 